TAO, Vol. 11, No. 4, 929-941, December 2000

\title{
Determination of P-Wave Velocity Structures, Earthquake Hypocenters, and Focal Mechanisms in the Morgan Hill Region of Central California
}

\author{
Cheng-Horng Lin ${ }^{1, *}$ and Steven W. Roecker ${ }^{2}$ \\ (Manuscript received 5 June 2000, in final form 16 October 2000)
}

\begin{abstract}
P-wave velocity structure, earthquake hypocenters, and focal mechanisms are investigated by applying an analytic ray tracing technique to 2437 $\mathbf{P}$-wave arrivals from 154 locally recorded earthquakes from the Morgan Hill region of central California. Taking as our reference the results of a previous investigation by Michael (1988) on the effects of laterally varying structure on these parameters of hypocenters and focal mechanisms, we found that to the first order the principal structures are preserved, but that features associated with the fault zone tend to be better focused and of higher contrast when the analytic ray tracer is used. In particular, the low velocities associated with the Madrone Springs and Calaveras faults are confined to a narrow zone of about $5 \mathrm{~km}$ width. Contrasts in velocities associated with this zone are $2-3 \%$ larger at shallow depth. These contrasts gradually decrease with depth, but are evident to depths of at least $12 \mathrm{~km}$. Hypocenters relocated in this structure shift systematically to the east by 1-2 km and their depths generally increase by as much as $5 \mathbf{~ k m}$. The combined effect of the epicenter and depth shift is to decrease the apparent dip of the seismic zone by $4^{\circ}$ and to move the surface intercept of the seismic zone to the east by $0.8 \mathrm{~km}$. Compared with those determined by approximate ray tracing, initial ray directions calculated with the analytic ray tracer are within $\pm 5^{\circ}$ in azimuth but can be as much as $30^{\circ}$ different in take-off angle. The danger of attempting focal mechanism analysis with only a few arrivals is therefore evident. The effects of these differences on the deduced focal mechanisms themselves appear to be on the order of $10^{\circ}$ in the strike and dip of the probable fault plane.
\end{abstract}

(Key words: Tomography, Hypocenter, Focal Mechanism, Morgan Hill)

\footnotetext{
${ }^{1}$ Institute of Earth Sciences, Academia Sinica, Nankang, Taipei, Taiwan, ROC

${ }^{2}$ Dept. of Earth and Environmental Sciences, Rensselaer Polytechnic institute, Troy, NY 12180 USA

${ }^{*}$ Corresponding author address: Dr. Cheng-Horng Lin, Institute of Earth Sciences, Academia Sinica, P.

O. Box 1-55, Nankang, Taipei, Taiwan, ROC; E-mail: lin@earth.sinica.edu.tw
} 


\section{INTRODUCTION}

The existence of strong lateral variations in elastic wave velocity structure within the broad system of faults that make up the Pacific-North American plate boundary in central California has been documented in a number of studies using data from both explosive (e.g., Blumling et al. 1985; Mooney and Colburn 1985; Walter and Mooney 1982) and earthquake (e.g., Wesson 1971; Healy and Peake1975; Thurber 1983) sources. It has also been suggested by a number of investigators that these variations in structure play some role in controlling the size, and perhaps frequency, of earthquakes along various parts of the boundary, and this has motivated seismologists to determine the details of structural variations along these faults. In many cases, however, the methods used in determining these variations make assumptions about the smoothness of the structure that may be untenable, and hence may gloss over the real picture or introduce artifacts into the interpreted results. The potentially dramatic effects on ray paths of laterally varying structure, such as may be found in central California have been demonstrated by several investigators (e.g., Engdahl and Lee 1976; Feng and McEvilly 1983). Such demonstrations lead one to suspect that approximate ray tracing techniques, although popular in their efficiency, may contaminate any result with modeling noise. At the same time, other investigators (e.g., Michael 1988) argue that for several types of observables (hypocenters and focal mechanisms in particular) the use of a three-dimensional vs. a onedimensional model is of little consequence. In this study we examine the effects of using an analytic ray tracer in determining hypocenters and focal mechanisms in the region of the 24 April 1984 Morgan Hill earthquake, using as data the arrival times of $\mathrm{P}$ waves produced by the main and aftershocks of this event recorded by a network of local stations. The ray tracer used (Lin and Roecker 1997) is designed to produce accurate rays in regions where velocities change rapidly.

The region ruptured by the 1984 Morgan Hill earthquake is characterized by a number of subparallel strike-slip faults, the most prominent of these being the Calaveras fault (Fig. 1). In the northern part of the region the Calaveras is well defined, but is buried in the south beneath the Quaternary sediments of the Santa Clara valley and appears to splay into a number of faults, apparently in an effort to reorganize itself into a more efficient strike slip system (Page 1984). Principal among these faults is the Madrone Springs fault, which bounds the Quaternary sediments to the east, separating them from the Franciscan formation. The Franciscan is the dominant geologic formation in this area, being prominent everywhere to the east of the Calaveras and Madrone Springs faults and to the west of the Silver Creek fault, and disappearing beneath the Cretaceous marine sediments of Santa Clara valley in between.

An unresolved issue in this part of the zone is the dip of the active faults, in particular of the Calaveras, in this area. The focal mechanism of the 1984 mainshock shows a rupture plane that dips between vertical and about $85^{\circ}$ to the southwest, while earthquake hypocenters generally define a plane that dips $85^{\circ}$ to the northeast. Moreover, it is not clear with which, if any, of the mapped faults these earthquakes should be associated. Michael (1988; hereafter referred to as M88) examined the possibility that the earthquakes could be mislocated by methods employing one-dimensional earth models. Moreover, he determined that focal mechanisms from aftershocks of this event were not sensitive to the model used. 


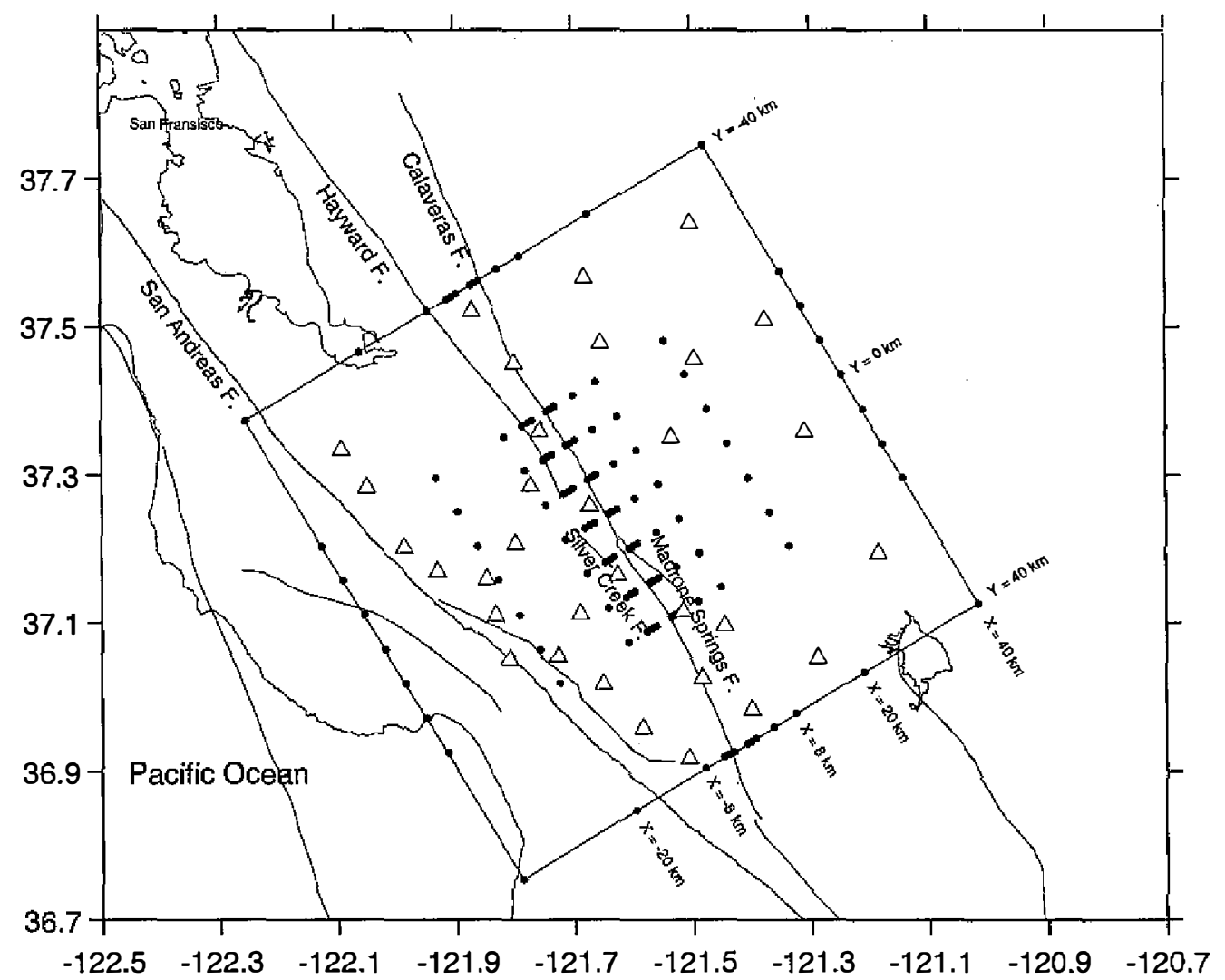

Fig. 1. Map of Morgan Hill and surrounding regions, showing locations of velocity nodes as closed circles and locations of stations used in this study as open triangles. Numbers at the edges of the grid indicate positions of the nodes with respect to the center of coordinates $\left(37.25^{\circ} \mathrm{N}, 121.635^{\circ} \mathrm{W}\right)$.

The principal objective of this study is to examine to what extent the use of an analytic ray tracing technique with different model parameterizations and damping, and in particular one that is better suited to racing in regions with very large lateral gradients in structure, can have on the determination of structure, hypocenters, and focal mechanisms. In addition to its intrinsic interest from geological and seismological points of view, we decided to do this work in the Morgan Hill area because severe lateral variations in structure are well documented and because a fair amount of analysis has already been done by M88. Our approach is to analyze the same data set as M88, so that results may be compared directly. Generally, we find that while most of the gross features determined by M88 are robust, the effects of more accurate ray tracing are to improve the focus in areas of large velocity contrast. Hypocenters are found to shift by $1-2 \mathrm{~km}$ in epicenter and up to $5 \mathrm{~km}$ in depth. Focal mechanisms are robust as long as a large number of observations outside of the fault zone are used in determining them. Differences in strike, dip, and rake are on the order of 5-10 ${ }^{\circ}$. However, mechanisms produced 
with only a few observations, or which are controlled by only a few observations, should be regarded with suspicion.

\section{METHODOLOGY AND DATA}

In this study, a seismic tomography technique is employed to determine simultaneously hypocenter locations and velocity structure through the analysis of $\mathrm{P}$-wave arrival times of locally recorded earthquakes. A distinguishing element of the method employed here is the method used to compute ray paths and travel times. The Circular Ray Tracer (CRT), described in detail in Lin and Roecker (1997), is an analytical ray-racing method that parameterizes the Earth as a series of tetrahedra, within each of which the velocity varies linearly, as

$$
V(x, y, z)=V_{0}+b_{i} x+b_{2} y+b_{3} z
$$

The specification of velocities at each of the four nodes of the tetrahedra is sufficient to determine the coefficients in the equation above. The tetrahedra are arranged in such a way that any 8 nodes in the corners of a rectangular prism define 6 tetrahedra. An implication of this parameterization is that a given node can be an element of as many as 24 tetrahedra, which introduces an element of smoothing (and stability) into the inversion procedure. Thus, rays can be traced rapidly through regions with large gradients in velocity without worrying about the effects of numerical approximations.

A standard least-squares algorithm similar to that described by Tarantola and Valette (1982) is used to compute perturbations, because the gradient in velocity between nodes allows a fairly complicated model to be specified by a relatively small number of variables. Locations and origin times of the hypocenters used are decoupled from the velocity variables using the parameter separation technique of Pavlis and Booker (1980) and are determined separately by relocation subsequent to each perturbation in structure.

The data used in this study are the arrival times of $\mathrm{P}$ waves recorded by a local network of seismographs in the Morgan Hill region. In order to facilitate a comparison of results we started with the aftershocks selected by M88 in his study of Morgan Hill structure. We parsed this dataset to reduce clustering, as the information from closely occurring events would be largely redundant. By requiring that the distance between any two hypocenters be greater than $1 \mathrm{~km}$, we reduced the total number of earthquakes from 271 to 154 . The final data set consists of a total of 2437 arrival time observations. The best quality arrival times have associated uncertainties of $\pm 0.01 \mathrm{~s}$. Lower quality arrivals are included in the analysis but are weighted accordingly. The overall standard deviation of the expected uncertainties is about $\pm 0.05 \mathrm{~s}$.

The area chosen for the study is an $80 \times 80 \mathrm{~km}$ region centered on the Morgan Hill aftershock zone (Fig. 1). Thirty-two stations are located within this model. The three-dimensional model is defined by a grid of $13 \times 9$ nodes, which is much denser in the vicinity of the main faults, in each of five layers (Fig. 1). Differences in station elevation are explicitly accounted for by embedding stations within the structure (i.e., the first grid layer is located above the highest station). The grid is rotated so that the $\mathrm{Y}$-axis is parallel to the general strike of the 
Calaveras fault $\left(\mathrm{S} 31^{\circ} \mathrm{E}\right)$ in this area. The density of grid points is greater in regions that were heavily sampled by ray coverage or where severe lateral heterogeneity is expected. For valid comparison with the results of M88, starting values of velocity at each of the grid points were adapted from those determined by $\mathbf{M} 88$.

\section{THREE-DIMENSIONAL VELOCITY STRUCTURE}

The velocity model discussed here was obtained after three iterations. The standard deviation in the travel time residuals in the final model is $0.03 \mathrm{~s}$, which corresponds to a $70 \%$ reduction of the original misfit. Convergence was rapid; changes in velocities at the third iteration are less than $\pm 0.05 \mathrm{~km} / \mathrm{s}$. The final standard deviation is close to the estimated uncertainty in the readings, and therefore all the available signal in the data appears to be modeled with the structure and hypocenters determined. Formal estimates of resolution and covariance show resolution diagonals generally greater than 0.7 and standard errors in velocity of less than $\pm 0.05 \mathrm{~km} / \mathrm{s}$.

One of the main objectives in producing a revised three-dimensional velocity structure for this region was to examine the differences of analytical ray tracing would make on the structure determined. Comparing plots of initial and final structures in map view (Fig. 2) and cross section (Fig. 3), we note that although in several regions the local differences in velocity can be quite large ( $\pm 20 \%$ ), to the first order the principal features determined by M88 are retained in the model derived here. For example, the low velocities between the Madrone Springs and the Calaveras faults remain, as do the high velocity regions under the Franciscan formation to the northeast of the Madrone Springs fault. Viewed in detail, however, some significant differences can be found. In particular, the low velocity zone west of the Calaveras now appears as an elongated feature that is more confined to the vicinity of the fault trace. Contrasts across this low velocity fault zone also appear to be significantly larger in the $3-7 \mathrm{~km}$ depth range (layers 3 and 4; Fig. 2). Viewed in cross section (Fig. 3), a distinctive fault zone of about $5 \mathrm{~km}$ width appears to extend from the surface to the base of the model (12 km depth). Generally, the boundaries of this zone correspond at the surface to the Calaveras or Madrone Springs and Silver Creek faults, and appear to be nearly vertical. Thus, while the very low velocities associated with the sedimentary rocks west of the Madrone Springs fault extend to depths of only $3-5 \mathrm{~km}$, velocities beneath this depth remain anomalously slow, suggesting that the accumulation of these low velocity sediments is related to a fault zone that extends throughout much of the crust.

\section{RELOCATED EARTHQUAKES}

The earthquakes used in determining the velocity structure were relocated in the velocity discussed above. A comparison of the relocated hypocenters with those reported by M88 (Fig. 4a) shows that the 154 relocated epicenters shift almost systematically to the east by $1-2 \mathrm{~km}$. Changes in depth range from $0-5 \mathrm{~km}$. Cross sections of these locations (Fig. 4b) show that 


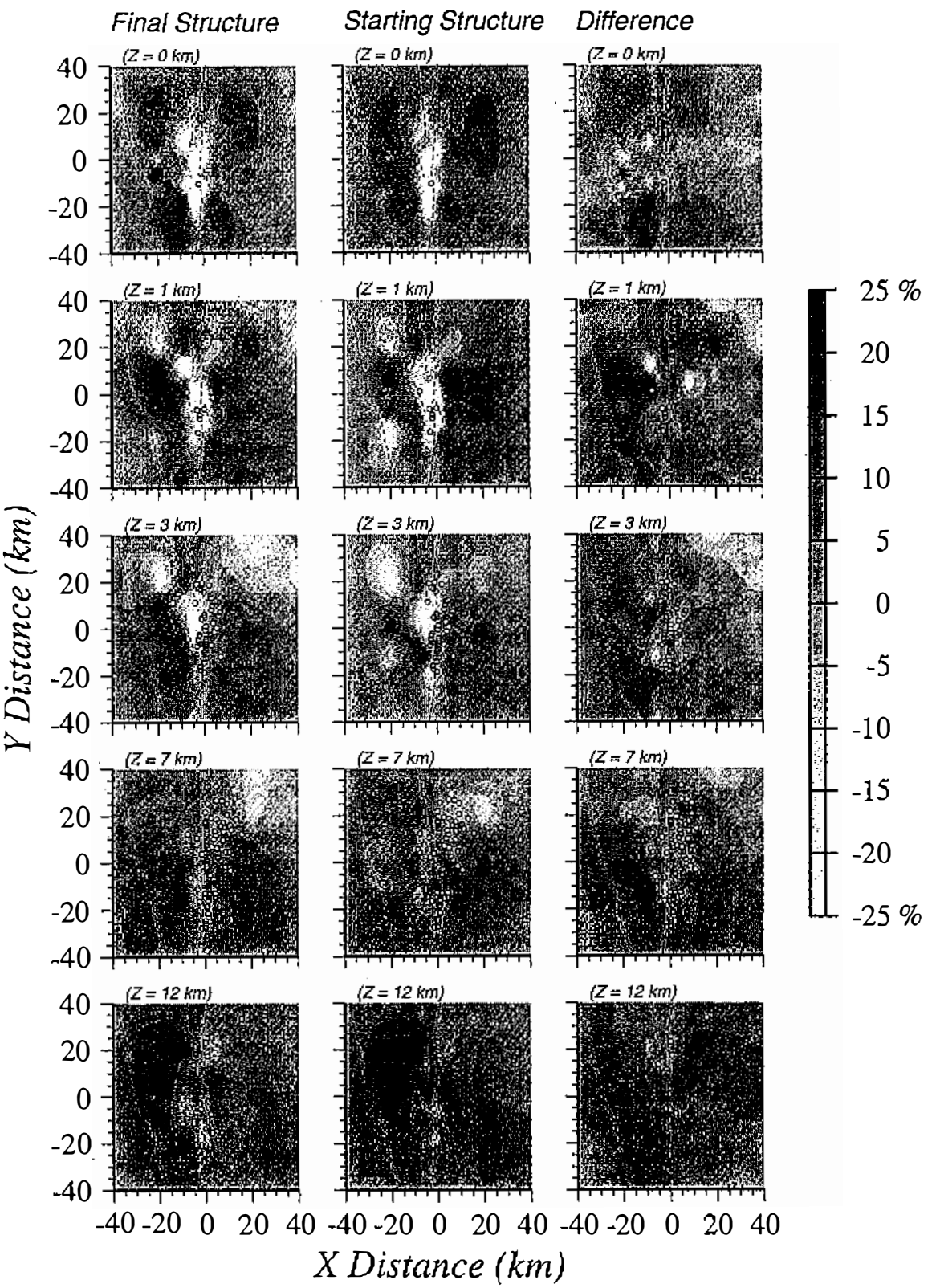

Fig. 2. Map view of perturbations of the final velocity structure (left), the starting model adapted from M88 (center) and the difference between the two (right). Shaded images are of percent difference between the final model and a 1D average of the depth range. Epicenters of relocated earthquakes are plotted as open circles. Dashed lines show fault traces. Coordinate axes show distance in kilometers from the center of coordinates, as shown in Fig. 1. 


\section{Final Profiles}

\section{Starting Profiles}

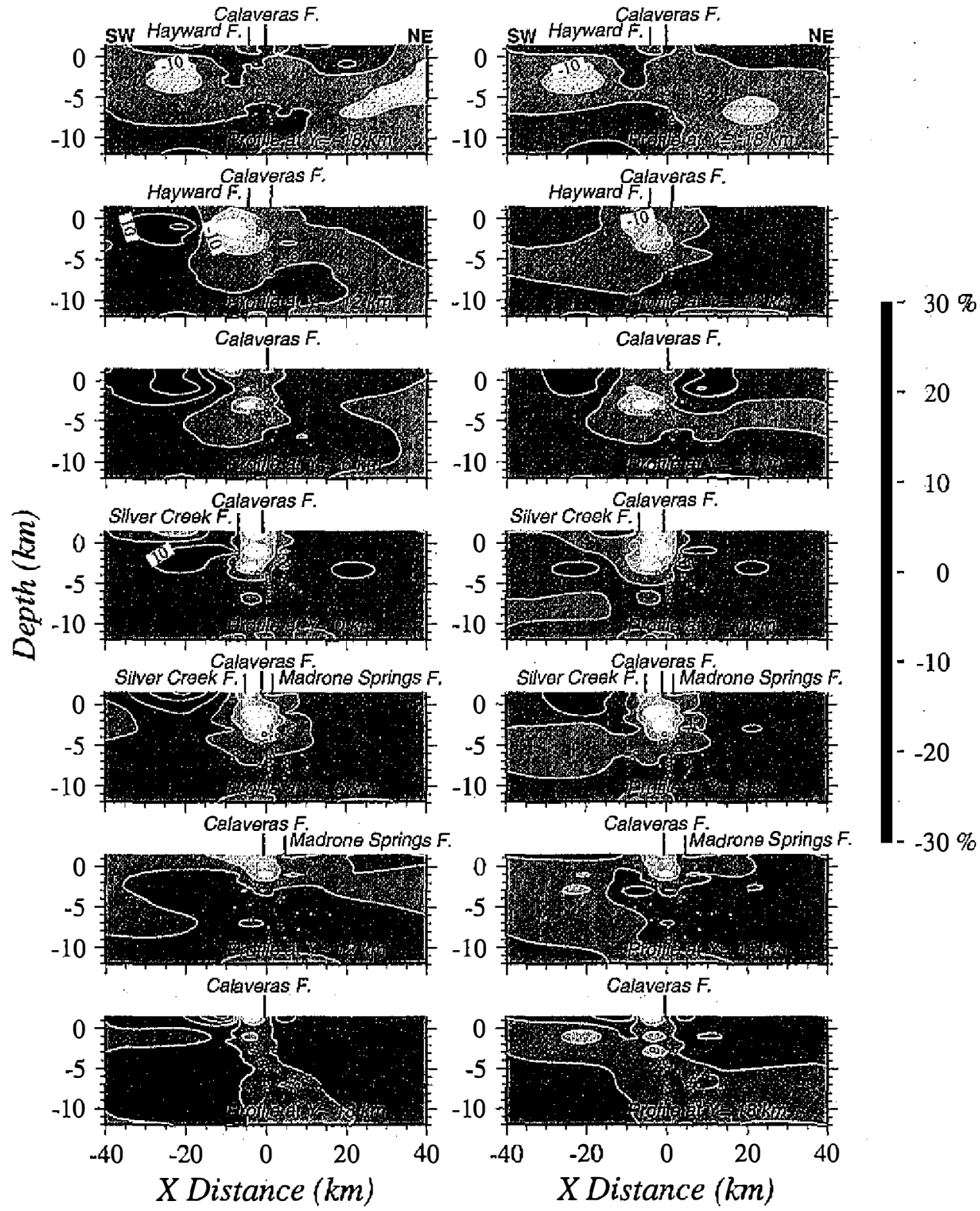

Fig. 3. Cross sections perpendicular to the Y-axis (SW-NE) of both starting and the final velocity perturbation model. The location of each section is indicated by the $\mathrm{Y}$ coordinate and corresponds to those shown in Fig. 1. Shaded images are of percent difference between the final model and a $1 \mathrm{D}$ average of the depth"jange. Locations of relocated earthquakes are plotted as open circles. 


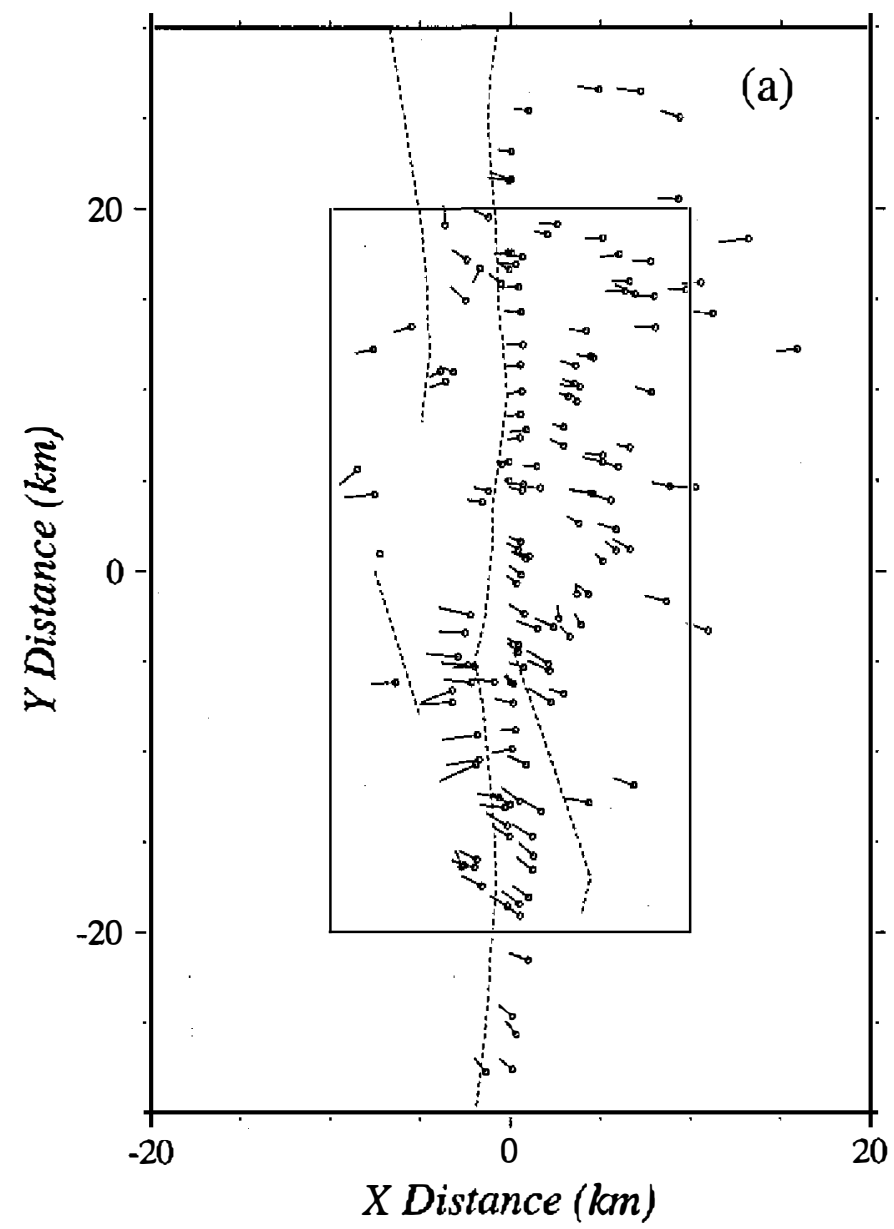

Fig. 4. Comparison of hypocenters of original locations and relocations in the final model derived in this study. (a) Map view. The final locations are shown by an open circle, and are connected to the original location with a line extending from the center of the circle. Box shows the location of the section plotted in Fig. 4b. (b) Cross section. The change in apparent dip of the seismic zone is indicated by the lines in each figure.

(b)

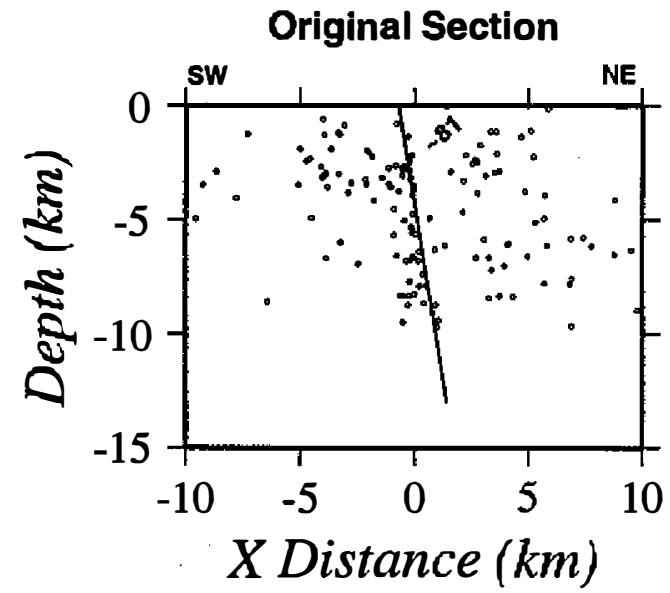

Relocated Section

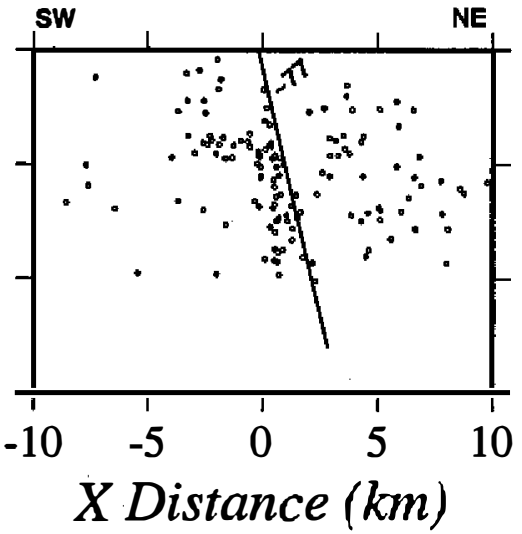


changes in depth vary with depth, with shallow events changing the most and deeper events changing the least. This depth dependent shift in depth decreases the dip of the seismic zone by about $4^{\circ}$, while the epicentral shift moves the intersection of the race of the seismic zone with the surface to the east by about $0.8 \mathrm{~km}$. Thus, while the locations of the hypocenters change by several kilometers, their relative precision is sufficient to constrain the dip of the seismic zone to within $1^{\circ}-2^{\circ}$. This result corroborates M88's assertion that the Calaveras fault is not vertical, but dips to the northeast at about $80^{\circ}$.

\section{RAY PATHS AND FOCAL MECHANISMS}

The accuracy of focal mechanisms deduced from the polarity of first motions depends upon our ability to estimate ray directions at the source. The influence of laterally varying structure across the San Andreas fault on focal mechanisms was investigated by McNalley and McEvilly (1977), who determined that inaccurate ray directions could be responsible for nodal planes that are incorrect by as much as $20^{\circ}$. On the other hand, M88 compared focal mechanisms from Morgan Hill determined in a one-dimensional model with those in a three-dimensional model using an approximate three-dimensional ray tracer and concluded that there was little if any significant difference between the mechanisms produced by the two. To examine the effects of analytical three-dimensional ray tracing on focal mechanisms in Morgan Hill, we produced plots of ray directions and focal mechanisms deduced from our model. A comparison of ray directions calculated in the three-dimensional model derived here by the analytic ray tracer with those calculated in a "best average" one-dimensional model (Fig. 5) shows that differences in azimuth generally are not great $\left( \pm 5^{\circ}\right)$, but that the differences in take-off angle can be significant $\left( \pm 30^{\circ}\right)$. To see how these differences in ray direction affect our estimates of individual focal mechanisms, we plotted the mechanisms for two of the earthquakes examined by M88 (Fig. 6; Table 1). These revised mechanisms show differences in strike and dip of about $10^{\circ}$. We note that the dips of the more probable focal planes (those with negative strikes) of the revised mechanisms are closer to the dip of the seismic zone inferred from the relocated aftershocks (about $80^{\circ}$ ).

As a final example of the effects of ray tracing on focal mechanisms, we tried the same type of analysis suggested by Cockerham and Eaton (1987) to find a "best location" for the mainshock based on the polarity of a few stations that showed first motions inconsistent with the focal mechanism of the main event. Based on their analysis, they chose location "D" (Fig. 7) as the most probable. However, when the effects of laterally varying structure are taken into account, location " $D$ " does not appear to be any more attractive than the others.

\section{DISCUSSIONS}

Does the use of a sophisticated ray tracer with different model parameterizations and damping make a significant difference in the tomographic analysis of data from a region with strong lateral heterogeneity? In regions like Morgan Hill, where a relatively high density of observations are available, the differences may be considered second order but nevertheless 


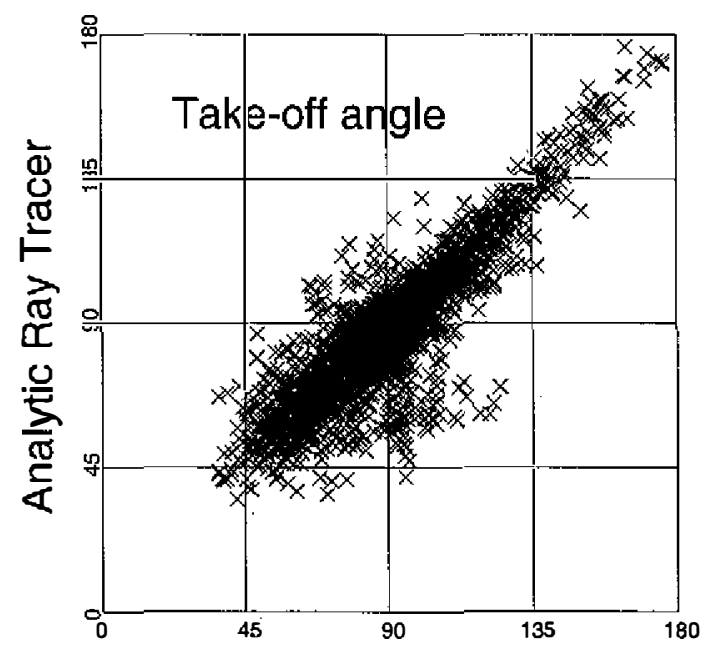

Approximate Ray Tracer

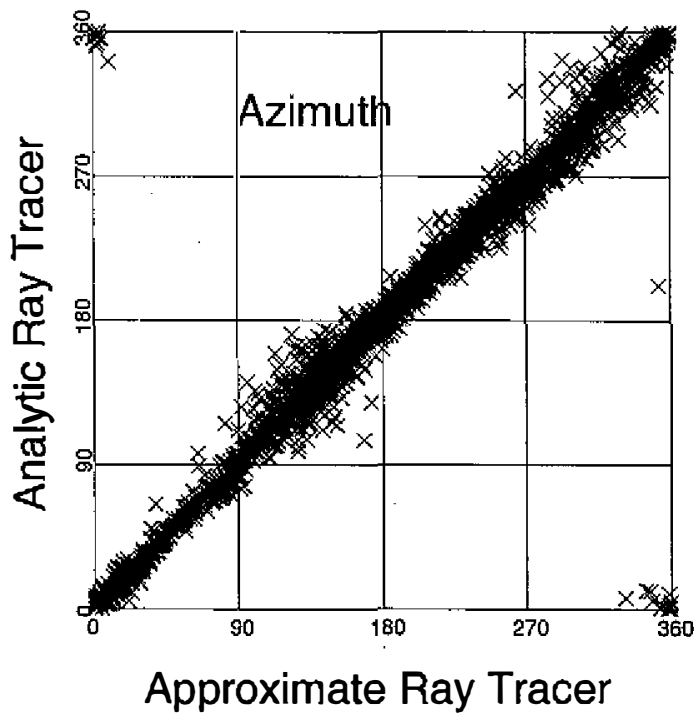

Fig. 5. Comparison of ray directions (take-off angle and azimuth) computed with the analytic ray tracer and an approximate ray tracer.
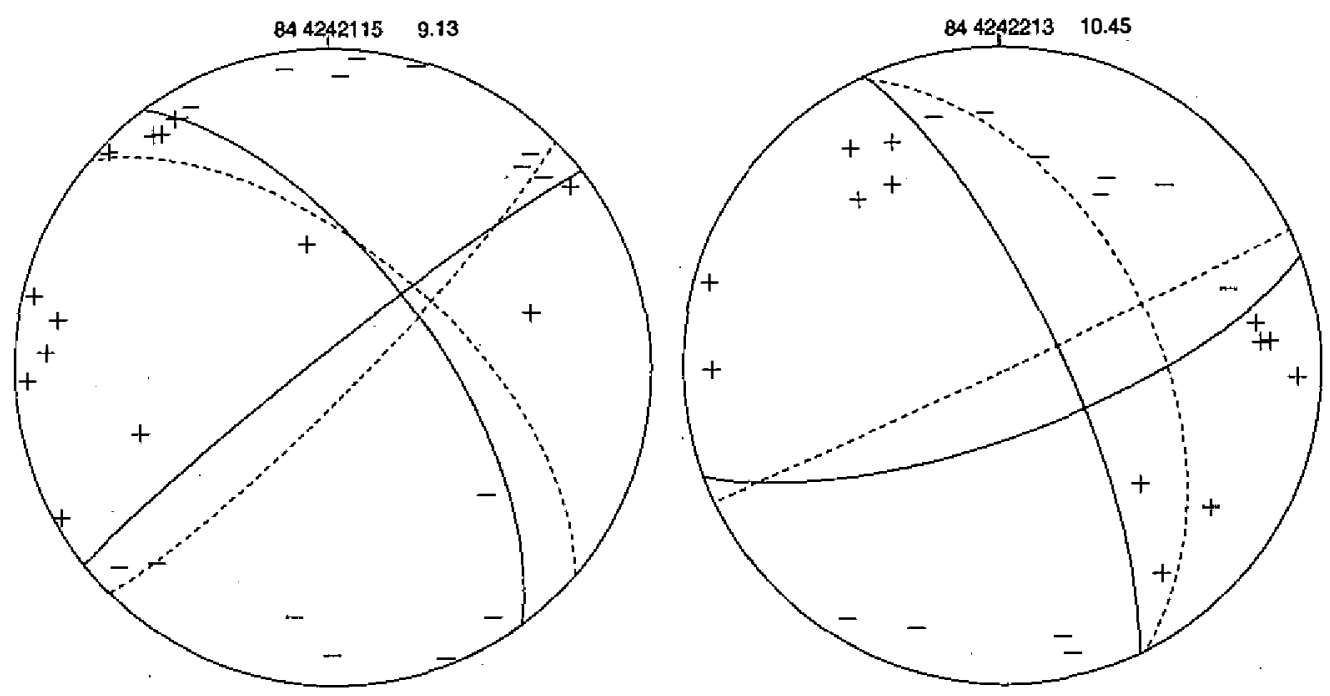

Fig. 6. Comparison of two focal mechanisms determined in this study with those of M88. Plots are made using the ray directions calculated with the analytic ray tracer. The solutions from M88 are shown by the dashed lines, while those from the present study are shown by the solid lines. Focal mechanism parameters are shown in Table 1. 
Table 1. Summary of focal mechanism parameters for the solutions shown in Fig. 6.

\begin{tabular}{|c|c|c|c|c|c|c|c|c|}
\hline \multirow{3}{*}{$\begin{array}{l}\text { Events } \\
\text { (Date) }\end{array}$} & \multicolumn{4}{|c|}{ Original FPS } & \multicolumn{4}{|c|}{ Redefined FPS } \\
\hline & \multicolumn{2}{|c|}{ Plane 1} & \multicolumn{2}{|c|}{ Plane 2} & \multicolumn{2}{|c|}{ Plane 1} & \multicolumn{2}{|c|}{ Plane 2} \\
\hline & Strike & Dip & Strike & Dip & Strike & Dip & Strike & Dip \\
\hline 8404242115 & $-49^{\circ}$ & $60^{\circ}$ & $45^{\circ}$ & $83^{\circ}$ & $-36^{\circ}$ & $64^{\circ}$ & $52^{\circ}$ & $-86^{\circ}$ \\
\hline 8404242213 & $-26^{\circ}$ & $50^{\circ}$ & $65^{\circ}$ & $89^{\circ}$ & $-25^{\circ}$ & $75^{\circ}$ & $70^{\circ}$ & $72^{\circ}$ \\
\hline
\end{tabular}
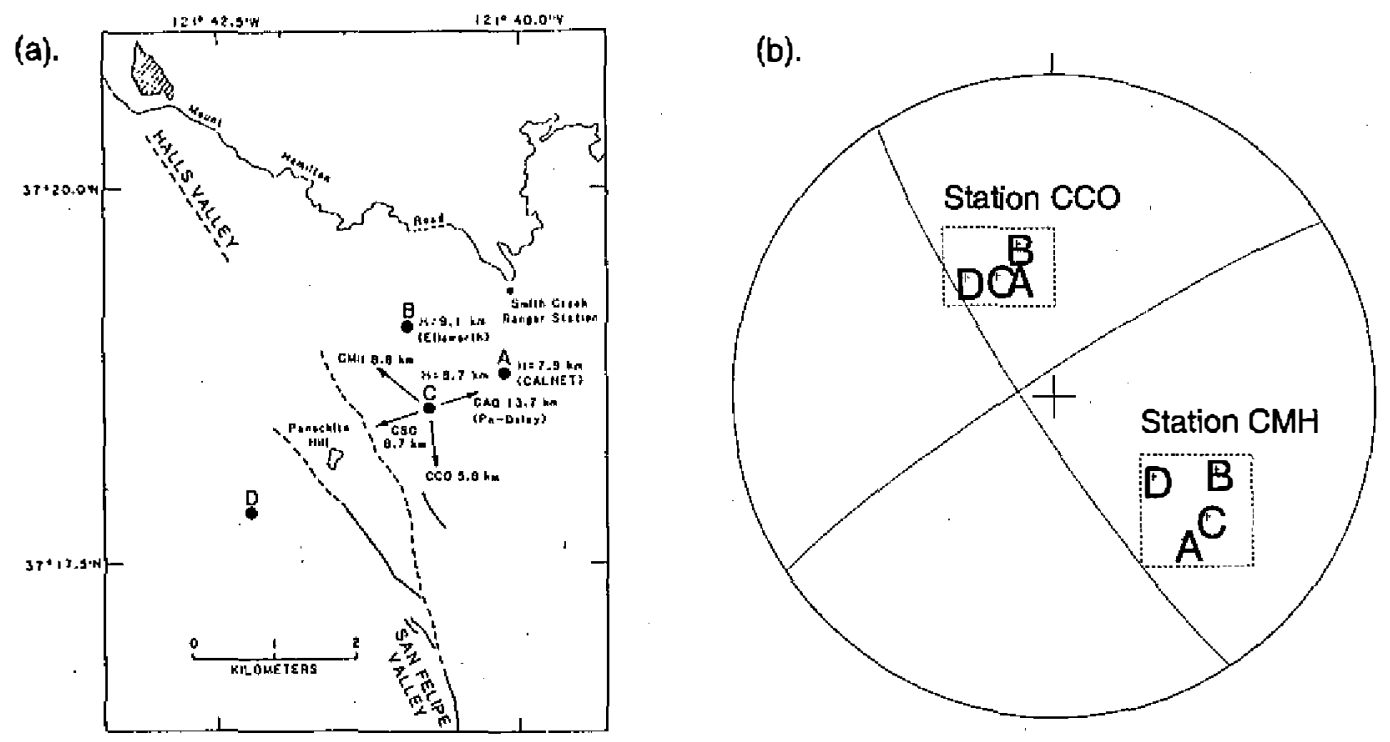

Fig. 7(a). The four trial locations A, B, C, and D of the main shock tested by Cockerham and Eaton [1987]. (b) Plot of rays to stations CCO and CMH from these mainshock locations using the analytic ray racer and the model derived in this study. Note that these rays do not appear to constrain the location of the mainshock. 
can be significant in a variety of applications. For example, while most of the main structural features determined by M88 were found to be robust, the improvement in contrast and focus tells us more about the nature of the fault zone and could be useful, for example, in the modeling of fault zone guided waves (e.g., Li et al. 1997). Hypocenter locations change by a few kilometers, which can be important when trying to understand the relation between the seismic zone and the surface trace of a particular fault. For example, offsets such as we observe here (on the order of 100s of meters) between the fault trace and the intercept of the seismic zone with the surface imply that the fault at shallow depths is not planar. We note that a similar offset was found for the San Andreas Fault in the nearby Bear Valley region (e.g., Lin and Roecker 1997; Thurber et al. 1997). At the same time, the relative precision of the locatios was largely unaffected; the strike and dip of the seismic zone changed by only a degree or so. Focal mechanism parameters changed by about $10^{\circ}$, which is a similar amount of variation found by M88 in his comparison of the effects of one- and three-dimensional structures. While not a large change, such refinements can lead to a better understanding between individual ruptures and the geometry of the seismic zone. In this case, the correlation between the probable rupture planes and the orientation of the seismic zone improved significantly. Finally, because the observed stability of first order deductions from analyses using approximate ray tracing depends to a large extent on the density of seismographs available, one may expect regions that are less densely populated with seismographs will benefit to a greater extent from accurate ray tracing.

Acknowledgments We received a lot of help in organizing the data set used in this study from several colleagues at the USGS in Menlo Park. We especially appreciate the efforts and guidance provided by Bill Ellsworth, David Oppenheimer, and Fred Klien. Additional insights were derived from discussions with Cliff Thurber. This work was supported by USGS Contract 14-08-0001-G1697. This was also partially supported by Institute of Earth Sciences, Academia Sinica.

\section{REFERENCES}

Blumling, P., W. D. Mooney, and W. H. K. Lee, 1985: Crustal structures of the southern Calaveras fault zone, central California, from seismic refraction. Bull. Seism. Soc. Am., 75, 193-209.

Cockerham, R. S., and J. P. Eaton, 1987: The earthquake and its aftershocks, April 24 through September 30, 1984, in The Morgan Hill, California, Earthquake of April 24, 1984, U. S. Geol. Surv. Bull. 1639. In: S. N. Hoose (Ed.), U.S. Geological Survey, Menlo Park, California, 15-28.

Engdahl, E. R., and W. H. K. Lee, 1976: Relocation of local earthquakes by seismic ray racing. J. Geophys. Res., 81, 4400-4406.

Feng, R., and T. V. McEvilly, 1983: Interpretation of seismic reflection profiling data for the structure of the San Andreas fault zone. Bull. Seism. Soc. Am., 73, 1701-1720.

Healy, J. H., and L. G. Peake, 1975: Seismic velocity structures along a section of the San Andreas fault near Bear Valley, California. Bull. Seism. Soc. Am., 65, 1177-1197. 
Li, Y.-G., W. L. Ellsworth, C. H. Thurber, P. Malin, and K. Aki, 1997: Fault-zone guided waves from explosions in the San Andreas fault at Parkfield and Cienega Valley, Califormia. Bull. Seism. Soc. Am., 87, 210-221.

Lin, C. H. and S. W. Roecker, 1997: Three-dimensional P-wave velocity structure of the Bear valley region of central California. PAGEOPH, 149, 667-688.

McNally, K. C., and T. V. McEvilly, 1977: Velocity conrast across the San Andreas fault in central California: Small-scale variations from P-wave model plane distortion, Bull. Seism. Soc. Am., 67, 1565-1576.

Michael, A., 1988: Effects of three-dimensional velocity structure in the seismicity of the 1984 Morgan Hill, California, aftershock sequence. Bull. Seism. Soc. Am., 78, No. 3, 1199-1221.

Mooney, W. D., and R. H. Colbum, 1985: A seismic refraction profile across the San Andreas, Sargent, and Calaveras faults, west-central California. Bull. Seism. Soc. Am., 75, 175191.

Page, B. M. (1984), The Calaveras fault zone of California, an active plate boundary element, in The 1984 Morgan Hill, California Earthquake, California Division of Mines and Geology, Speicial Publication 68, J.H. Bennett and R.W. Sherburne,Editors, Sacramento, California, 109-122.

Pavlis, G. L., and J. R. Booker, 1980: The mixed discrete-continous inverse problem: Application to the simultaneous determination of earthquake hypocenters and velocity structure. J. Geophys. Res., 87, 945-959.

Tarantola, A., and D. Gubbins, 1982: Inverse problems = Quest for information. J. Geophys., 50, $159-170$.

Thurber, C. H., 1983: Earthquake locations and three-dimensional crustal structure in the Coyote Lake Area, central Califomia. J. Geophys. Res., 88, 8226-8236.

Thurber, C. H., S. W. Roecker, W. Ellsworth, Y. Chen, W. Lutter, and R. Sessions, 1997: Two-dimensional seismic image of the San Andreas fault in the Northem Gabilan Range, central California: evidence for fluids in the fault zone. Geophys. Res. Lett., 24, 15911594.

Walter, A. W., and W. D. Mooney, 1982: Crustal structure of the Diablo and Gabilan Ranges, central California: A reinterpretation of existing data. Bull. Seism. Soc. Am., 72, 15671590.

Wesson, R. T., 1971: Travel-time inversion for laterally inhomogeneous crustal velocity models. Bull. Seism. Soc. Am., 61, 729-746. 